\title{
Digestão de carboidratos em equinos alimentados com dietas compostas de volumoso ou de volumoso suplementado com concentrado e/ou óleo de soja
}

\author{
[Carbohydrate digestion in horses fed diets composed by roughages or roughages supplemented with \\ concentrate and/or soybean oil] \\ E.S. Morgado ${ }^{1}$, F.Q. Almeida ${ }^{2}$, F.N. Godoi ${ }^{1}$, A.V.C. Gomes ${ }^{3}$, L. Galzerano ${ }^{1}$, \\ A.B. França ${ }^{4}$, L.S. Brasileiro ${ }^{5}$ \\ ${ }^{1}$ Aluno de pós-graduação - UFRRJ - Seropédica, RJ (Bolsista CAPES) \\ ${ }^{2}$ Instituto de Veterinária - UFRRJ - Seropédica, RJ (Pesquisador CNPq) \\ ${ }^{3}$ Instituto de Zootecnia - UFRRJ - Seropédica, RJ \\ ${ }^{4}$ Aluno de graduação - UFRRJ - Seropédica, RJ (Bolsista PIBIC-CNPq) \\ ${ }^{5}$ Aluno de graduação - UFRRJ - Seropédica, RJ (Bolsista IC-FAPERJ)
}

\begin{abstract}
RESUMO
Determinaram-se as frações dos carboidratos não fibrosos, hidrolisáveis e rapidamente fermentáveis em diferentes dietas e estimou-se a digestibilidade aparente desses nutrientes em dois ensaios com equinos. No ensaio I, utilizaram-se quatro equinos em delineamento quadrado latino $4 \times 4$, que consumiram dietas compostas por: feno de tifton-85; feno de tifton- 85 e feno de alfafa; feno de tifton-85, feno de alfafa e concentrado; feno de tifton- 85 e concentrado. No ensaio II, utilizaram-se 15 equinos em delineamento inteiramente casualizado, que consumiram dietas com 5,13 e $21 \%$ de extrato etéreo, obtidos com a inclusão de diferentes proporções de óleo de soja. A inclusão de concentrado nas dietas aumentou a digestibilidade dos carboidratos não fibrosos e de suas frações, sem afetar a digestibilidade da fibra, enquanto, em dietas com $13 \%$ de extrato etéreo, a digestibilidade das frações dos carboidratos fibrosos e a dos não fibrosos não foram afetadas. Nas dietas com $21 \%$ de extrato etéreo, houve redução na digestibilidade da celulose e dos carboidratos não fibrosos e suas frações hidrolisáveis e rapidamente fermentáveis. A análise dos carboidratos não fibrosos é uma boa estimativa do valor nutricional dos alimentos, podendo ser incluída na avaliação da qualidade dos alimentos e dietas dos equinos.
\end{abstract}

Palavras-chave: equino, digestibilidade, forragem, lipídios

\begin{abstract}
The fractions of nonfiber carbohydrates, hydrolyzable carbohydrates, and rapidly fermentable carbohydrates of diets and the apparent digestibility of these nutrients were evaluated in horses in two digestion assays. In assay I, four horses in $4 x 4$ latin square diets: tifton-85 hay; tifton-85 hay and alfafa hay; tifton-85 hay, alfafa hay, and concentrate; and tifton-85 hay and concentrate. In assay II, fifteen horses were used in a completely randomized design, diets with 5, 13, and $21 \%$ ether obtained with the inclusion of different proportions of soybean oil. Results showed that inclusion of concentrate in diets increased digestibility of nonfiber carbohydrates, hydrolyzable carbohydrates, rapidly fermentable carbohydrates, and total carbohydrates, without affecting digestibility of fiber. In diets with $13 \%$ of ether extract in function of soybean oil inclusion, digestibility of fiber and nonfiber carbohydrates fractions was not affected; however, in diets with $21 \%$ of ether extract, the digestibility of cellulose, nonfiber carbohydrates, hydrolyzable carbohydrates and rapidly fermentable carbohydrates were reduced. Analysis of nonfiber carbohydrates fractions is a good estimate of feeds nutritional value, and could be included in quality evaluation of feeds and diets given to horses.
\end{abstract}

Keywords: digestibility, equine, forage, lipids

Recebido em 6 de novembro de 2008

Aceito em 2 de setembro de 2009

e-mail: almeidafa@yahoo.com.br

Apoio: CNPq/FAPERJ 


\section{INTRODUÇÃO}

Os carboidratos são os principais constituintes das plantas forrageiras e são extremamente importantes na dieta dos equinos. $\mathrm{O}$ processo de digestão nos equinos ocorre em duas etapas. Uma enzimática, no intestino delgado, denominada pré-cecal, onde os carboidratos são expostos a enzimas pancreáticas e intestinais que digerem as proteínas, lipídeos, e carboidratos não estruturais como amido, maltose e sacarose que serão hidrolisados e absorvidos como monossacarídeos. A outra etapa, microbiana, ocorre no intestino grosso, denominada pós-ileal, onde ocorre, principalmente, a digestão da fração fibrosa.

Os carboidratos das plantas podem ser agrupados em duas grandes categorias: os fibrosos e os não fibrosos. Os carboidratos fibrosos, celulose e hemiceluloses, juntamente com a lignina, compõem a parede celular vegetal e são lentamente digeridos. Apresentam disponibilidade nutricional variável e ocupam espaço no trato gastrintestinal. Os não fibrosos apresentam disponibilidade nutricional rápida, completa e constante entre os alimentos, isto é, de 98 a 100\% (Van Soest, 1967). São constituídos por amido, monossacarídeos, dissacarídeos, oligossacarídeos, frutanas, $\beta$ glucanas, galactanas e pectinas. No entanto, os mamíferos e outros animais de estômago simples não possuem enzimas próprias para hidrolisar frutanas, ligações $\beta$-glucanas, substâncias pécticas e oligossacarídeos. Esses carboidratos e outros polissacarídeos não-amiláceos podem ser fermentados pelos microrganismos do intestino grosso para produzir produtos microbianos de valor nutricional (Hall, 2003).

O sistema de avaliação de alimentos utilizado para equinos tem sido o mesmo usado para ruminantes, embora diferenças importantes devam ser observadas, quanto ao processo de digestão, devido a diferenças na compartimentalização do trato digestivo, que se traduz em digestão diferenciada dos alimentos (Smolders et al., 1990), tornando inapropriada para os equinos a análise proximal dos carboidratos utilizada para ruminantes.

Com a finalidade de desenvolver um sistema mais adequado à fisiologia digestiva dos equinos, Hoffman et al. (2001) propuseram o fracionamento dos carboidratos mais adequado à fisiologia digestiva de animais com fermentação no intestino grosso, dividindo-os em frações hidrolisáveis, que produzem a glicose absorvida pelo intestino delgado, e fração dos carboidratos fermentáveis, que produzem principalmente acetato, propionato e butirato, oriundos da fermentação microbiana no intestino grosso. Essa fração pode ser subdividida em fibras rapidamente fermentáveis, que incluem frutanas, substâncias pécticas e $\beta$-glucanas e fibras lentamente fermentáveis, representadas pelo resíduo insolúvel em detergente neutro.

O fornecimento de grandes quantidades de amido nas dietas dos equinos compromete sua digestão no intestino delgado, aumentando a quantidade de carboidratos rapidamente fermentáveis no ceco-cólon, que pode resultar em complicações metabólicas como endotoxemias, cólicas e laminites (Nutrient ..., 2007). Potter et al. (1992) citaram que a capacidade crítica para a sobrecarga da digestão dos carboidratos hidrolisáveis é de, aproximadamente, $0,4 \%$ do peso vivo dos equinos.

Segundo Kronfeld et al. (1994), a substituição de carboidratos hidrolisáveis, que é a fração dos carboidratos não fibrosos composta por açúcares simples e amido, por uma dieta rica em fibra e lipídios, possui vantagens na redução de desordens digestivas, melhoria no desempenho e no comportamento dos equinos.

O objetivo deste trabalho foi avaliar a digestibilidade das frações dos carboidratos hidrolisáveis, rapidamente fermentáveis e lentamente fermentáveis em ensaios de digestão com equinos alimentados com dietas suplementadas com concentrado e/ou com óleo de soja.

\section{MATERIAL E MÉTODOS}

Este trabalho foi constituído por dois ensaios de digestão em equinos. No ensaio I, os equinos foram suplementados com ração concentrada, e, no ensaio II, os animais receberam dietas com inclusão de óleo de soja. No ensaio I, foram utilizados quatro potros machos mestiços, não castrados, com média de peso de $200 \mathrm{~kg}$ e média de idade de 30 meses, em delineamento em quadrado latino 4x4. Esses animais foram submetidos à doma de baixo, sendo exercitados, 
a passo e trote, uma vez por dia, por 30 minutos no período da manhã. As dietas foram formuladas considerando o consumo dietético diário equivalente a $2 \%$ do peso vivo dos animais (Nutrient ..., 1989). As dietas experimentais utilizadas foram: dieta I, composta por tifton-85 (Cynodon dactylon ssp); dieta II, composta por feno de tifton-85 e feno de alfafa (Medicago sativa) na proporção 50:50; dieta III, composta por $30 \%$ de feno de tifton- $85,30 \%$ de feno de alfafa e $40 \%$ de concentrado, na relação volumoso:concentrado de 60:40; e dieta IV, composta por $60 \%$ feno de tifton- 85 , compondo o volumoso e $40 \%$ de concentrado (Tab. 1).

As dietas foram oferecidas quatro vezes ao dia, em partes iguais, às $1 \mathrm{~h}, 7 \mathrm{~h}, 13 \mathrm{~h}$ e $19 \mathrm{~h}$, e a água e o suplemento mineral foram fornecidos à vontade. $\mathrm{O}$ ensaio de digestão consistiu de quatro períodos experimentais, cada período composto por 19 dias, sendo 14 dias de adaptação às dietas e cinco dias de coleta total de fezes.

Tabela 1. Dietas experimentais e composição percentual da matéria seca e carboidratos fibrosos e não fibrosos de cada dieta (D)

\begin{tabular}{lcccc}
\hline \multicolumn{1}{c}{ Ingrediente (\%) } & $\begin{array}{c}\text { Tifton-85 } \\
\text { (D I) }\end{array}$ & $\begin{array}{c}\text { Tifton-85 } \\
\text { alfafa } \\
\text { (D II) }\end{array}$ & $\begin{array}{c}\text { Tifton-85 + } \\
\text { alfafa + } \\
\text { concentrado I } \\
\text { (D III) }\end{array}$ & $\begin{array}{c}\text { Tifton-85 + } \\
\text { concentrado II } \\
\text { (D IV) }\end{array}$ \\
\hline Feno de alfafa & 0,0 & 50,0 & 30,0 & 0,0 \\
Feno de tifton-85 & 100,0 & 50,0 & 30,0 & 60,0 \\
Milho & 0,0 & 0,0 & 32,5 & 27,5 \\
Farelo de soja & 0,0 & 0,0 & 6,5 & 11,5 \\
Fosfato bicálcico & 0,0 & 0,0 & 0,0 & 0,2 \\
Premix & 0,0 & 0,0 & 0,4 & 0,3 \\
Sal & 0,0 & 0,0 & 0,2 & 0,2 \\
Inerte & 0,0 & 0,0 & 0,4 & 0,3 \\
\hline \multicolumn{1}{c}{ Nutriente (\% na MS) } & & & & 84,1 \\
\hline Matéria seca & 83,9 & 84,1 & 84,3 & 48,6 \\
Fibra em detergente neutro & 72,3 & 63,6 & 43,8 & 26,5 \\
Fibra em detergente ácido & 40,6 & 39,5 & 25,4 & 22,0 \\
Hemiceluloses & 31,7 & 24,1 & 18,4 & 28,8 \\
Carboidratos não fibrosos & 8,3 & 12,6 & 33,4 & 15,3 \\
Carboidratos hidrolisáveis & 2,4 & 2,6 & 19,2 & 13,4 \\
Carboidratos rapidamente fermentáveis & 5,9 & 9,9 & 14,2 & 77,4 \\
Carboidratos totais & 80,6 & 76,2 & 77,2 & \\
\hline Ca: & 580 P: & & & \\
\hline
\end{tabular}

${ }^{\mathrm{C}} \mathrm{Ca}$ : 180g; P: 70g; S: 12g; Mg: 10g: Na: 115g; Fe: 4.500mg; Cu: 2000mg; Zn: 3000mg; Mn: 1000mg; I: 180mg; Se: 12mg; Co: 40mg; Lisina: 10g, vit.A (UI): 40mg; vit. E (UI): 400mg; F: 700mg.

No ensaio II, foram utilizados 15 equinos mestiços, oito machos e sete fêmeas, com média de idade de 7,6 $\pm 3,5$ anos, média de peso de $457 \pm 31 \mathrm{~kg}$, em delineamento experimental inteiramente ao acaso, com três tratamentos (dietas) e cinco repetições (animais). Os animais foram exercitados nas modalidades de adestramento e salto, seguindo a rotina de exercícios da Escola de Equitação do Exército. As dietas foram formuladas para equinos em atividade física moderada segundo o NRC (Nutrient ..., 1989) e consistiram na inclusão de três níveis de óleo de soja. A dieta I $(5 \%$ de extrato etéreo) foi composta por concentrado comercial, farelo de soja, mistura mineral, sal comum e feno de coastcross (Cynodon dactilon L. Pers); a Dieta II (13\% de extrato etéreo) por concentrado comercial, farelo de soja, mistura mineral, sal comum e feno de coastcross com inclusão de $8,5 \%$ de óleo de soja; e a dieta III (21\% de extrato etéreo) por concentrado comercial, farelo de soja, mistura mineral, sal comum, feno de coastcross e inclusão de 19,5\% de óleo de soja (Tab. 2). 
Tabela 2. Dietas (D) experimentais e composição percentual em matéria seca, carboidratos fibrosos e não fibrosos de cada dieta

\begin{tabular}{lccc}
\hline \multicolumn{1}{c}{ Ingrediente (\%) } & D I & D II & D III \\
$(5 \%$ EE) & 65,4 & 47,1 & 25,8 \\
\hline Concentrado comercial & 0,9 & 10,0 & 20,1 \\
Farelo de soja & 0,0 & $8,5^{1}$ & $19,5^{2}$ \\
Óleo de soja & 0,7 & 1,4 & 1,9 \\
Sal (NaCl + Sal Mineral) & 33,0 & 33,0 & 33,0 \\
Feno de coastcross & 100 & 100 & 100 \\
Total & & & \\
\hline \multicolumn{1}{c}{ Nutriente (\%) } & 90,4 & 91,0 & 92,2 \\
\hline Matéria seca & 53,4 & 46,9 & 39,3 \\
Fibra em detergente neutro & 22,7 & 21,1 & 19,2 \\
Fibra em detergente ácido & 30,6 & 25,9 & 20,3 \\
Hemiceluloses & 14,6 & 13,5 & 12,2 \\
Celulose & 20,7 & 18,2 & 15,1 \\
Carboidratos não fibrosos & 12,2 & 9,7 & 6,7 \\
Carboidratos hidrolisáveis & 8,5 & 8,5 & 8,4 \\
Carboidratos rapidamente fermentáveis & 74,1 & 65,1 & 54,4 \\
Carboidratos totais & &
\end{tabular}

${ }^{\mathrm{T}}$ Corresponde a $720 \mathrm{~mL}$ de óleo de soja $;{ }^{2}$ corresponde a $1.440 \mathrm{~mL}$ de óleo de soja.

O concentrado foi parcialmente retirado nas dietas hiperlipidêmicas em função da inclusão do óleo de soja e do aumento da energia dietética, sendo necessária a redução nas quantidades de feno de coastcross aos equinos, visando manter a mesma relação de concentrado:volumoso (67:33) em todas as dietas. O farelo de soja foi acrescentado nas dietas para manter a relação proteína bruta (PB):energia de $40 \mathrm{~g}$ de $\mathrm{PB} / \mathrm{Mcal}$ energia digestível (Nutrient ..., 1989).

O óleo de soja, o farelo de soja, a mistura mineral e o sal comum foram adicionados no momento do fornecimento da ração concentrada. $\mathrm{O}$ fornecimento diário da dieta foi parcelado em cinco vezes, sendo o concentrado fornecido três vezes ao dia, às $4 \mathrm{~h}, 13 \mathrm{~h}$ e $20 \mathrm{~h}$, e o feno de coastcross fornecido duas vezes, às $11 \mathrm{~h}$ e $16 \mathrm{~h}$, seguindo a rotina do manejo alimentar da Unidade Militar.

O ensaio de digestibilidade teve duração de 34 dias, sendo 30 dias de adaptação dos equinos às dietas e quatro dias de coleta total de fezes. As fezes de cada animal foram coletadas a cada seis horas, pesadas, homogeneizadas, e retirada uma alíquota referente a $10 \%$ do peso total, totalizando quatro amostras por animal por dia, armazenadas em sacos plásticos e mantidas sob refrigeração. Ao término de cada dia de coleta, as quatro amostras diárias de cada animal foram homogeneizadas e delas retirada uma amostra composta diária, as quais, em seguida, foram congeladas a $-10^{\circ} \mathrm{C}$. As amostras de alimentos e as sobras foram coletadas durante cada período experimental e armazenadas a $-10^{\circ} \mathrm{C}$ para posteriores análises.

Determinaram-se matéria seca (MS), matéria mineral (MM), extrato etéreo (EE) e proteína bruta $(\mathrm{PB})$, segundo a metodologia descrita pela AOAC (Official ..., 1995), e fibra em detergente neutro (FDN) e fibra em detergente ácido (FDA) segundo Van Soest et al. (1991).

Os carboidratos hidrolisáveis (CHO-H) foram estimados pela análise direta, segundo Hoffman et al. (2001), que consiste na determinação quantitativa dos carboidratos pela conversão dos polissacarídeos, sacarose e frutose em unidades de glicose redutoras, com um mínimo de extração e hidrólise dos carboidratos estruturais. Uma subamostra de aproximadamente $250 \mathrm{mg}$ foi levada à fervura com água destilada para a 
extração de hexoses livres. A amostra foi incubada com solução enzimática, constituída pela enzima takadiastase, uma $\alpha$-amilase proveniente do fungo Aspergilus orizae, à temperatura de $40-45^{\circ} \mathrm{C}$, por 44 horas, em que os dissacarídeos e o amido foram hidrolisados a moléculas de hexoses. Após a incubação, a solução foi filtrada em papel de filtro faixa preta, e o filtrado tratado com $2 \mathrm{~mL}$ de acetato de chumbo neutro $10 \%$ (peso/vol) usado para precipitar a proteína da amostra. As hexoses no sobrenadante foram analisadas por poder redutor, em que unidades redutoras obtidas foram utilizadas na redução do $\mathrm{Cu}^{++}$, precipitado como $\mathrm{Cu}_{2} \mathrm{O}$, e o excesso de cobre ficou livre na solução. Em seguida, foi feita a determinação iodométrica do excesso de cobre pela titulação com solução de tiossulfato de sódio, em presença de solução indicadora de amido, segundo Smith (1969), citado por Silva e Queiroz (2002).

Os carboidratos não fibrosos (CNF) foram estimados pela diferença, após a análise proximal, por meio da fórmula: $\mathrm{CNF}=100-\mathrm{PB}$ EE-MM-FDN. Os carboidratos rapidamente fermentáveis (CHO-RF) foram calculados pela diferença entre os carboidratos não fibrosos e os carboidratos hidrolisáveis. Os carboidratos totais (CHO-T) foram calculados pelo somatório dos carboidratos hidrolisáveis, carboidratos rapidamente fermentáveis e fibra em detergente neutro.
Os valores dos coeficientes de digestibilidade aparente dos nutrientes dos ensaios de digestão foram submetidos à análise de variância e comparados pelo teste $S N K$, adotando o nível de $5 \%$ de probabilidade. As análises estatísticas foram procedidas utilizando o programa SAEG (Sistema ..., 2007).

\section{RESULTADOS E DISCUSSÃO}

Os coeficientes de digestibilidade aparente dos nutrientes no ensaio I são apresentados na Tab. 3. A inclusão de concentrado à dieta aumentou de forma significativa a digestibilidade da matéria seca. Este resultado está de acordo com o encontrado por Pagan et al. (1998) e Miraglia et al. (2006). O aumento pode ser explicado pela redução do teor de fibra nas dietas com a inclusão de ração concentrada e aumento dos teores de carboidratos não fibrosos e de suas frações que apresentaram alta digestibilidade. Os coeficientes de digestibilidade da matéria seca das dietas utilizadas neste experimento com inclusão de concentrado foram de 60,4 e 65,4\% para as dietas III e IV, respectivamente. Valores próximos foram verificados por Pagan et al. (1998), de 62,1\% para uma dieta mista de forragem e concentrado, e por Miraglia et al. (2006), de 57,4 e 61,2\% para dietas com diferentes relações de volumoso e concentrado.

Tabela 3. Valores médios do coeficiente de digestibilidade aparente dos nutrientes das dietas fornecidas aos equinos com inclusão de concentrado (ensaio I)

\begin{tabular}{lcccc}
\hline \multicolumn{1}{c}{$\begin{array}{c}\text { Coeficiente de } \\
\text { digestibilidade (\%) }\end{array}$} & $\begin{array}{c}\text { Tifton-85 } \\
\text { (DI) }\end{array}$ & $\begin{array}{c}\text { Tifton-85 } \\
+ \text { alfafa } \\
\text { (DII) }\end{array}$ & $\begin{array}{c}\text { Tifton-85 }+ \\
\text { alfafa }+ \\
\text { concentrado I } \\
\text { (DIII) }\end{array}$ & $\begin{array}{c}\text { Tifton-85 }+ \\
\text { concentrado II } \\
\text { (DIV) }\end{array}$ \\
\hline Matéria seca & $47,2 \pm 1,9 \mathrm{~b}$ & $48,9 \pm 2,5 \mathrm{~b}$ & $60,4 \pm 4,1 \mathrm{a}$ & $65,4 \pm 0,7 \mathrm{a}$ \\
Fibra em detergente neutro & $42,6 \pm 1,8 \mathrm{a}$ & $41,9 \pm 2,8 \mathrm{a}$ & $39,0 \pm 6,5 \mathrm{a}$ & $49,6 \pm 2,0 \mathrm{a}$ \\
Fibra em detergente ácido & $41,4 \pm 1,6 \mathrm{a}$ & $40,4 \pm 3,4 \mathrm{a}$ & $36,4 \pm 6,1 \mathrm{a}$ & $49,1 \pm 0,9 \mathrm{a}$ \\
Hemiceluloses & $45,3 \pm 1,2 \mathrm{a}$ & $42,3 \pm 3,4 \mathrm{a}$ & $43,8 \pm 7,3 \mathrm{a}$ & $50,3 \pm 0,2 \mathrm{a}$ \\
Carboidratos não fibrosos & $76,1 \pm 4,9 \mathrm{~b}$ & $74,5 \pm 3,6 \mathrm{~b}$ & $92,6 \pm 1,1 \mathrm{a}$ & $91,4 \pm 0,9 \mathrm{a}$ \\
Carboidratos hidrolisáveis & $68,0 \pm 4,6 \mathrm{~b}$ & $75,2 \pm 2,7 \mathrm{~b}$ & $94,1 \pm 0,9 \mathrm{a}$ & $93,2 \pm 1,2 \mathrm{a}$ \\
Carboidratos rapidamente fermentáveis & $77,9 \pm 6,8 \mathrm{~b}$ & $74,2 \pm 5,1 \mathrm{~b}$ & $91,8 \pm 2,0 \mathrm{a}$ & $90,3 \pm 1,8 \mathrm{a}$ \\
Carboidratos totais & $47,6 \pm 1,9 \mathrm{~b}$ & $47,4 \pm 2,3 \mathrm{~b}$ & $62,2 \pm 4,1 \mathrm{a}$ & $65,9 \pm 0,7 \mathrm{a}$ \\
\hline
\end{tabular}

Médias seguidas de letras diferentes na linha diferem entre si pelo teste $\mathrm{SNK}(\mathrm{P}<0,05)$.

Não foi observado efeito da adição de concentrado ao alimento volumoso na digestibilidade dos constituintes da parede celular, FDN, FDA e hemiceluloses. Resultados contraditórios foram observados na literatura por
Pagan et al. (1998), Drogou et al. (2001) e Miraglia et al. (2006), que verificaram redução da digestibilidade da fibra com a inclusão de concentrado à dieta. Essa diferença pode ser atribuída à qualidade da fibra do concentrado 
utilizado nos experimentos e à quantidade desse componente na dieta.

Os valores da digestibilidade da FDN de 41,9 e $39,0 \%$ foram observados para as dietas II e III, respectivamente. Holland et al. (1998), ao alimentarem equinos com fenos de orchardgrass e de alfafa e com essas mesmas forragens mais a inclusão de concentrado, verificaram valores da digestibilidade da FDN de 53,2 e 42,2\%, respectivamente. Pagan et al. (1998) avaliaram dieta exclusiva de forragem e dieta com inclusão de concentrado e observaram valores de digestibilidade da FDN de 40,9 e 34,6\%, respectivamente. Miraglia et al. (1999), ao utilizarem dietas com relação volumoso e concentrado de 67:33, sendo o alimento volumoso composto por uma mistura de gramíneas e leguminosas na alimentação de equinos, observaram valores de digestibilidade da FDN e FDA de 46,6 e 40,8\%, respectivamente, situação experimental semelhante à do presente trabalho, em que a relação concentrado volumoso foi de 60:40.

Os coeficientes de digestibilidade aparente dos carboidratos não fibrosos e suas frações hidrolisáveis e rapidamente fermentáveis aumentaram $(\mathrm{P}<0,05) \quad$ com a inclusão de concentrado nas dietas, com valores acima de $90 \%$, em comparação às dietas com apenas alimentos volumosos. $\mathrm{O}$ menor teor de carboidratos fibrosos e o maior teor de carboidratos não fibrosos, hidrolisáveis e rapidamente fermentáveis nas dietas III e IV com a inclusão de concentrado, podem ter influenciado o aumento da digestibilidade desses nutrientes.

Houve aumento $(\mathrm{P}<0,05)$ na digestibilidade dos carboidratos totais, 14,8 e 18,3 pontos percentuais, respectivamente, em DIII e DIV em relação à DI, que pode ser explicado pelo aumento na digestibilidade dos carboidratos não fibrosos e suas frações que fazem parte do total dos carboidratos.

Pagan et al. (1998) e Holland et al. (1998) observaram que a adição de concentrado em dietas para equinos aumenta a digestibilidade dos carboidratos não fibrosos em comparação às dietas exclusivas com alimentos volumosos e atribuíram esse fato à maior concentração de carboidratos não fibrosos e ao menor teor de fibra em dietas mistas, o que explica os resultados encontrados no presente trabalho.

Moore e Dehority (1993) relataram que não foram observadas diferenças na concentração de bactérias celulolíticas cecal em pôneis que receberam dietas com $90 \%$ de feno e $10 \%$ de concentrado comparado com pôneis que recebiam $60 \%$ feno e $40 \%$ de concentrado; no entanto, a maior quantidade de concentrado na dieta foi associada com aumento da quantidade das bactérias totais. Isso pode explicar, neste ensaio de digestão, a pouca influência da adição de concentrado na digestibilidade da fibra da dieta e o aumento da digestibilidade dos carboidratos não fíbrosos com a inclusão de concentrado na dieta.

Os valores médios dos coeficientes de digestibilidade aparente das dietas com diferentes níveis de inclusão de óleo de soja estão apresentados na Tab. 4. A inclusão de óleo de soja nas dietas não afetou os coeficientes de digestibilidade aparente da MS, FDN, FDA e hemiceluloses. No entanto, diferenças $(\mathrm{P}<0,05)$ foram observadas nos coeficientes de digestibilidade aparente dos carboidratos totais, carboidratos não fibrosos e suas frações hidrolisáveis e rapidamente fermentáveis, além da celulose, isto é, a digestibilidade dessas frações foi maior nos equinos que consumiram a dieta com maior nível de inclusão de óleo de soja.

O valor médio do coeficiente de digestibilidade aparente dos carboidratos não fibrosos na dieta com $5 \%$ de extrato etéreo, sem inclusão de óleo de soja, com relação volumoso:concentrado de $67: 33$ foi de $96,5 \%$, semelhante ao observado no ensaio I na dieta composta por $60 \%$ de tifton- 85 e $40 \%$ de concentrado, de $91,4 \%$.

Segundo Meyer (1995), fontes lipídicas de alta digestibilidade, como os óleos vegetais, podem ser totalmente digeridas no intestino delgado e não alcançaram o intestino grosso, o que poderia alterar a microflora e prejudicar a digestibilidade da fibra. Resende Jr. et al. (2004), ao utilizarem adição crescente de óleo na dieta de equinos nos níveis de $0 ; 2,9 ; 5,7$ e $8,3 \%$ da dieta total, não observaram alterações da digestibilidade da MS, FDN e FDA. 
Tabela 4. Valores médios do coeficiente de digestibilidade aparente dos nutrientes das dietas (D) com diferentes níveis de inclusão de óleo de soja (ensaio II)

\begin{tabular}{lccc}
\multicolumn{1}{c}{$\begin{array}{c}\text { Coeficientes de } \\
\text { digestibilidade (\%) }\end{array}$} & $\begin{array}{c}5 \% \mathrm{EE} \\
\text { (DI) }\end{array}$ & $\begin{array}{c}13 \% \mathrm{EE} \\
(\mathrm{DII})\end{array}$ & $\begin{array}{c}21 \% \mathrm{EE} \\
(\mathrm{DIII})\end{array}$ \\
\hline Matéria seca & $62,3 \pm 2,5 \mathrm{a}$ & $62,6 \pm 1,5 \mathrm{a}$ & $62,7 \pm 3,2 \mathrm{a}$ \\
Fibra em detergente neutro & $53,6 \pm 2,9 \mathrm{a}$ & $48,4 \pm 2,1 \mathrm{a}$ & $40,8 \pm 4,3 \mathrm{a}$ \\
Fibra em detergente ácido & $41,3 \pm 2,6 \mathrm{a}$ & $35,9 \pm 2,9 \mathrm{a}$ & $30,7 \pm 4,5 \mathrm{a}$ \\
Hemiceluloses & $62,7 \pm 3,3 \mathrm{a}$ & $58,6 \pm 1,5 \mathrm{a}$ & $50,5 \pm 4,2 \mathrm{a}$ \\
Celulose & $50,1 \pm 2,6 \mathrm{a}$ & $42,9 \pm 2,0 \mathrm{a}$ & $31,7 \pm 5,2 \mathrm{~b}$ \\
Carboidratos não fibrosos & $96,5 \pm 1,8 \mathrm{a}$ & $87,3 \pm 2,5 \mathrm{a}$ & $69,9 \pm 6,3 \mathrm{~b}$ \\
Carboidratos hidrolisáveis & $97,7 \pm 0,4 \mathrm{a}$ & $97,3 \pm 0,4 \mathrm{a}$ & $91,9 \pm 2,2 \mathrm{~b}$ \\
Carboidratos rapidamente fermentáveis & $94,9 \pm 3,9 \mathrm{a}$ & $76,3 \pm 5,1 \mathrm{a}$ & $53,2 \pm 9,5 \mathrm{~b}$ \\
Carboidratos totais & $65,0 \pm 2,1 \mathrm{a}$ & $58,4 \pm 1,7 \mathrm{a}$ & $48,8 \pm 4,3 \mathrm{~b}$ \\
\hline
\end{tabular}

Médias seguidas de letras diferentes na linha diferem entre si pelo teste $\mathrm{SNK}(\mathrm{P}<0,05)$.

EE: extrato etéreo.

Jansen et al. (2000) avaliaram a substituição de carboidratos não estruturais (glicose e amido) na dieta com $2,5 \%$ de extrato etéreo por dieta com óleo de soja com $8,6 \%$ de extrato etéreo, o que equivaleria a $37 \%$ da energia líquida da dieta para equinos, e verificaram redução nos coeficientes de digestibilidade da FDN, FDA e da celulose, respectivamente em 5,3; 7,2 e 6,0 unidades percentuais. Essa redução, segundo Jansen et al. (2007), pode ser explicada pela inibição da atividade celulolítica das bactérias do ceco e/ou cólon dos equinos.

Na dieta com $13 \%$ de extrato etéreo, a inclusão de $720 \mathrm{~mL}$ de óleo de soja não reduziu $(\mathrm{P}>0,05)$ a digestibilidade dos carboidratos fibrosos e não fibrosos, demonstrando que a inclusão dessas quantidades de óleo não altera a digestibilidade dos carboidratos. No entanto, a inclusão do maior nível de óleo de soja, $21 \%$ de extrato etéreo na dieta, resultou na redução $(\mathrm{P}<0,05)$ na digestibilidade aparente dos carboidratos não fibrosos e da celulose, em 26,6 e 18,4 pontos percentuais, respectivamente.

O coeficiente de digestibilidade aparente dos carboidratos rapidamente fermentáveis foi o que apresentou maior redução $(\mathrm{P}<0,05)$, de $94,9 \%$ na dieta com $5 \%$ de extrato etéreo, para $53,2 \%$ na dieta com $21 \%$ de extrato etéreo, redução de 41,7 pontos percentuais. Estes carboidratos são constituídos por frutanas, pectinas, $\beta$-glucanas e galactanas que não são digeridos pelas enzimas digestivas dos equinos, porém, são fermentados pelos microrganismos presentes no intestino grosso. O menor valor de digestibilidade dos carboidratos rapidamente fermentáveis associado ao maior nível de inclusão do óleo de soja pode ser devido à alteração da microflora, ao reduzir a digestibilidade desses carboidratos. $\mathrm{O}$ fato de não terem sido observadas diferenças $(P>0,05)$ na digestibilidade da fibra em detergente neutro e fibra em detergente ácido mostra a importância de se fracionar os carboidratos não fibrosos, quando se pretende avaliar o aproveitamento da dieta.

\section{CONCLUSÕES}

O fracionamento dos carboidratos não fibrosos em hidrolisáveis e rapidamente fermentáveis facilita a estimativa do valor nutricional das dietas e pode ser utilizado na avaliação da qualidade dos alimentos e no balanceamento de dietas dos equinos. A adição de concentrado na proporção de $40 \%$ na dieta de equinos aumenta a digestibilidade dos carboidratos não fibrosos e suas frações, sem afetar a digestibilidade da fibra. A inclusão de óleo de soja em níveis de $21 \%$ de extrato etéreo na dieta reduz a digestibilidade da celulose, dos carboidratos não fibrosos e suas frações.

\section{REFERÊNCIAS BIBLIOGRÁFICAS}

DROGOUL, C.; DE FOMBELLE, A.; JULLIAND, V. Feeding and microbial disorders in horses: 2: effect of three hay:grain ratios on digesta passage rate and digestibility in ponies. $J$. Equine Vet. Sci., v.21, p.487-491, 2001.

HALL M.B. Challenges with nonfiber carbohydrate methods. J. Anim. Sci., v.81, p.3226-3232, 2003.

HOFFMAN, R.M.; WILSON, J.A.; KRONFELD, D.S. et al. Hydrolysable 
carbohydrates in pasture, hay, and horse feeds: direct assay and seasonal variation. J. Anim. Sci., v.79, p.500-506, 2001.

HOLLAND, J.L.; KRONFELD, D.S.; SKLAN, D. et al. Calculation of fecal kinetics in horses fed hay or hay and concentrate. J. Anim. Sci., v.76, p.1937-1944, 1998.

JANSEN, W.L.; VAN DER KUILEN, J.; GEELEN, S.N.J. et al. The effect of replacing nonstructural carbohydrates with soybean oil on the digestibility of fibre in trotting horses. Equine Vet. J., v.32, p.27-30, 2000.

JANSEN, W.L.; CONE, J.W.; GEELEN, S.N.J. et al. High fat intake by ponies reduces both apparent digestibility of dietary cellulose and cellulose fermentation by faeces and isolated caecal and colonic contents. Anim. Feed Sci. Tech., v.133, p.298-308, 2007.

KRONFELD, D.S.; FERRANTE P.L.; GRANDJEAN, D. Optimal nutrition for athletic performance, with emphasis on fat adaptation in dogs and horses. J. Nutr., v.124, p.2745S-2753S, 1994.

MEYER, H. (Ed.). Alimentação de cavalos. São Paulo: Varela, 1995. 303p.

MIRAGLIA, N.; BERGERO, D.; BASSANOB, B. et al. Studies of apparent digestibility in horses and the use of internal markers. Liv. Prod. Sci., v.60, p.21-25, 1999.

MIRAGLIA, N.; BERGERO, D.; POLIDORI, $M$. et al. The effects of a new fibre-rich concentrate on the digestibility of horse rations. Liv. Sci., v.100, p.10-13, 2006.

MOORE, B.E.; DEHORITY, B.A. Effects of diet and hindgut defaunation on diet digestibility and microbial concentrations in the cecum and colon of the horse. J. Anim. Sci., v.71, p.3350-3358, 1993.

NUTRIENT requirements of horses. 5.ed. Washington, DC: National Academic, 1989. 100 p.
NUTRIENT requirements of horses. 6.ed. Washington, DC: National Academic, 2007. $341 \mathrm{p}$.

OFFICIAL methods of analysis. 15.ed. Washington, DC: AOAC, 1990. 1141p.

PAGAN, J.D.; HARRIS, P.A.; BREWSTERBARNES, T. et al. Exercise affects digestibility and rate of passage of all-forage and mixed diets in thoroughbreds horses. J. Nutr., v.128, p.2704S-2707S, 1998.

POTTER, G. D.; ARNOLD, F. F.; HOUSEHOLDER, D. D. et al. Digestion of starch in the small or large intestine of the equine. Pferdeheilkunde, v.1, p.107-111, 1992.

RESENDE JÚNIOR, T.; REZENDE, A.S.C.; LACERDA JÚNIOR, O.V. et al. Efeito do nível de óleo de milho adicionado à dieta de equinos sobre a digestibilidade dos nutrientes. Arq. Bras. Med. Vet. Zootec., v.56, p.69-73, 2004.

SILVA, D.J.; QUEIROZ, A.C. Análise de alimentos: métodos químicos e biológicos. 3.ed. Viçosa: UFV, 2002. 235p.

SISTEMA de análises estatísticas e genéticas SAEG. Versão 9.1. Viçosa: UFV, 2007.

SMITH, D. Removing and analysing total nonstructural carbohydrates from plant tissue. Wisconsin. Agr. Exp. Sta. Res. Rep., v.41, p.1$11,1969$.

SMOLDERS, E.A.A.; STEG, A.; HINDLE, V.A. Organic matter digestibility in horses and its prediction. J. Agric. Sci., v.38, p.435-447, 1990.

VAN SOEST, P.J.; ROBERTSON J.P.; LEWIS, B.A. Methods for dietary fiber, neutral detergent fiber, and nonstarch polysaccharides in relation to animal nutrition. J. Dairy Sci., v.74, p.35833597, 1991.

VAN SOEST, P.J. Development of a comprehensive system of feed analyses and its application to forages. J. Anim. Sci., v.26, p.119, 1967. 